\title{
Abdominal Aortic Aneurysm Presenting as a Claudication
}

\author{
Si-Hoon Son ${ }^{1}$, Seok-Won Chung ${ }^{2}$, Kyoung-Tae Kim', Dae-Chul Cho ${ }^{1}$ \\ ${ }^{l}$ Department of Neurosurgery, Kyoungpook National University College of Medicine, Daegu, \\ ${ }^{2}$ Department of Neurosurgery, Daegu Wooridul Spine Hospital, Daegu, Korea
}

Back pain and radiating pain to the legs are the most common symptoms encountered in routine neurosurgical practice and usually originates from neurogenic causes including spinal stenosis. The clinial symptoms are often confused with symptoms of peripheral neuropathy, musculo-skeletal disease and vascular disease in elderly patients. Because it is not easy to distinguish out the cause of symptoms by only physical examination, routine spinal MRI is checked first to rule out the spinal diseases in most outpatient clinics. Although it is obvious that spinal MRI is a very strong tool to investigate the spinal circumferences, most spine surgeons ignore the importance of looking at all aspects of their imaging and of remembering the extra-spinal causes of radiculopathy. A 68-year-old man who presented with a sudden aggravated both leg claudication. Although his symptom was mimicked for his long standing neurogenic claudication due to spinal stenosis diagnosed previously, abdominal aortic aneurysm(AAA) was found on routine lumbar MRI and it was repaired successfully. We emphasize to spinal surgeons the importance of remembering to look wider on routine MRI images when considering differential diagnoses in the outpatient clinic and to remember the extra-spinal causes of radiculopathy, especially when encountering in elderly patients.

Key Words: Claudication • Abdominal aortic aneurysm

\section{INTRODUCTION}

Back pain and radiating pain to the legs are the most common symptoms encountered in routine neurosurgical practice and usually originates from neurogenic causes including spinal stenosis. However, especially in elderly patients, other causes including malignant condition, myelomatous disease and extra-spinal causes such as vascular disease must always be considered. Vascular claudication from peripheral vascular disease is sometimes difficult to distinguish from neurogenic claudication. Lower extremity peripheral arterial disease (LE-PAD), one of the main expressions of systemic atherosclerosis, is associated with a high risk of developing different part of vascular tree ${ }^{1,5)}$. Although it is rare that the cause of leg pain is life-threatening, it should not be overlooked or missed. This

\footnotetext{
- Received: October 22, 2013 - Revised: November 8, 2013

- Accepted: November 12, 2013

Corresponding Author: Seok-Won Chung, MD

Department of Neurosurgery, Daegu Wooridul Spine Hospital, 648

Gukchaebosang-ro, Jung-gu, Daegu 700-732, Korea

Tel: +82-53-212-3000, Fax: +82-53-212-3068

E-mail: neurochung79@gmail.com

(2This is an Open Access article distributed under the terms of the Creative

Commons Attribution Non-Commercial License (http://creativecommons.org/ licenses/by-nc/3.0/) which permits unrestricted non-commercial use, distribution, and reproduction in any medium, provided the original work is properly cited.
}

case report describes a 68-year-old man who presented with a sudden aggravated claudication. Although his symptom was mimicked for his long standing neurogenic intermittent claudication due to spinal stenosis diagnosed previously, abdominal aortic aneurysm (AAA) was found on routine lumbar spine magnetic resonance imaging (MRI) and it was the cause of leg pain.

\section{CASE REPORT}

A 68-year-old man visited our outpatient clinic with aggravated both leg pain caused by exercise but relieved by rest for several days. Two years previously, he had been diagnosed lumbar spinal stenosis for similar symptom. Taking a pain killer medication, his symptom has been tolerable with visual analogue scale (VAS) score about 2 or 3. Suddenly, the pain was aggravated to VAS score 8 several days ago and he visited our neurosurgical outpatient clinic. On the neurological examination, he complained of symmetric radiating pain on exercise which was relieved remarkably by rest. He had a left hemiparesis $4 / 5$ due to the sequelae of cerebral lacunar infarction occurred 15 years ago, but no recent developing weakness was checked. Straight leg raising test (SLRT) was unremarkable and deep tendon reflexes (DTR) of lower extremities were symmetric. 


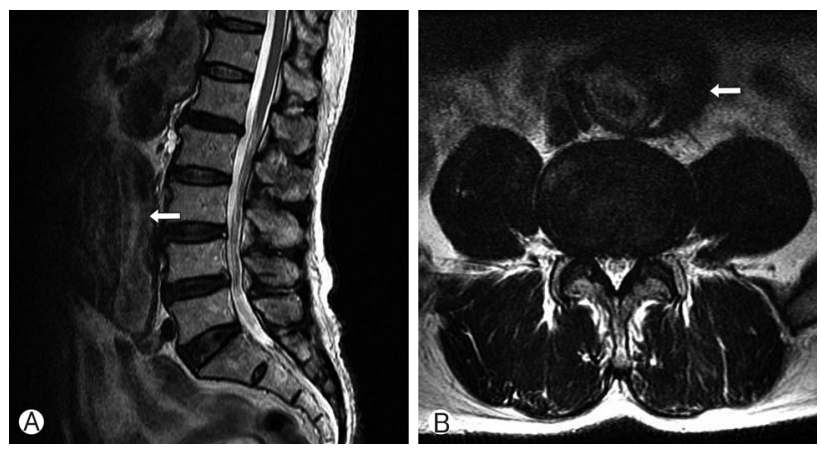

Fig. 1. Sagittal (A) and axial (B) T2-weighted MRI of lumbar spine demonstrate mild spinal stenosis due to hypertrophied ligamentum flavum. Moreover it also revealed huge sized abdominal aortic aneurysm (arrow).

Under the impression of lumbar spinal stenosis, routine lumbar MRI was checked and it revealed mild spinal canal stenosis caused by hypertrophy of ligamentum flavum on L4-5 (Fig. 1). Not only spinal lesion, it also revealed the huge sized AAA with luminal dilatation and inhomogeneous density inside which correlated to internal rupture of aneurysm. He referred to emergency room and notified to department of vascular surgery. To complete the imaging study, the vascular surgeon performed the abdominal computed tomography (CT) scan, which revealed a 70-mm-wide infra-renal aortic aneurysm (length approximately $20 \mathrm{~cm}$, from the origin of left renal artery to aorto-iliac bifurcation carrefour), with a signs of internal bleeding (Fig. 2). A final diagnosis of abdominal infra-renal aneurysm with internal bleeding was thus formulated. After preoperative evaluation including an ankle-brachial in$\operatorname{dex}(\mathrm{ABI})$ which decreased to 0.81 on right side and 0.88 on left side, he was sent to surgery (AAA repair with tube graft). His postoperative course was excellent and he is alive in good condition after 9 months. Moreover, the symptom, claudication on both leg, was improved to tolerable state (VAS 3), and $\mathrm{ABI}$ was improved to 1.10 on right side and 1.06 on left side postoperatively.

\section{DISCUSSION}

Radiculopathy, presented as a claudicant leg pain especially in elderly, is one of the most common symptoms encountered in the neurosurgical outpatient clinics. Most spine surgeons consider the symptom originated from spinal disease, like spinal stenosis, first and then peripheral vascular disease, like LE-PAD. In general, claudicant leg pain, from neurogenic or vascular, can be distinguished based on following several criteria. In the neurogenic claudication group, typical findings are: discomfort on lifting, bending, coughing or sneezing, pain
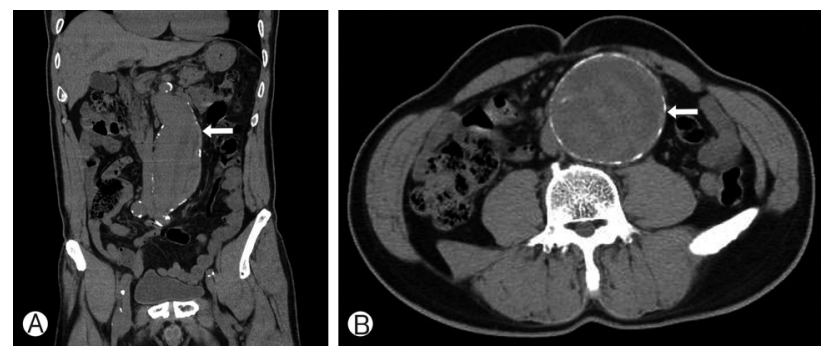

Fig. 2. Coronal (A) and axial (B) recontructed abdominal CT scan demonstrated abdominal infra-renal aortic aneurysm (arrow).

on standing, history of back injury, variable claudicating distance and segmental sensory loss, slow recovery by rest. In the vascular claudication group, characteristic distinguishing features include: abnormal foot pulses, arterial bruits, relief of symptoms by standing, a constant claudicating distance and stocking sensory loss, quick recovery by rest ${ }^{6}$. Claudication by peripheral vascular disease can be diagnosed simply and non-invasively via $\mathrm{ABI}$ measurement ${ }^{3)}$. The measurement involves placing sphygmomanometer cuff just above the ankle and using a Doppler instrument to measure the systolic pressure of the posterior tibial and dorsalis pedis arteries of each leg. The $\mathrm{ABI}$ is then obtained dividing the systolic pressure of each of the ankles by the highest brachial pressure of either $\mathrm{arm}^{7}$. A resting ABI value under 0.90 defines the presence of LE-PAD and it has a sensibility of about $95 \%$ in identifying the presence of a hemodynamically significant arterial stenosis at angiography between heart and foot and near 100\% specificity in excluding a normal subject ${ }^{10)}$.

Despite it is very important to distinguish out the causes of the pain, they are not clearly divided in the practical fields. Practically, many elderly patients have difficulty describing their symptoms precisely, and they usually have multiple different lumbar syndromes affecting their legs, including neurogenic claudication, acute or chronic lateral zone nerve root compression, and non-radicular lower extremity pain. Add to this fact, some of them have neurogenic and vascular claudication simultaneously, and even a peripheral neuropathy. Consequently, routine spinal MRI is checked first to rule out the spinal diseases in most outpatient clinics. Although it is obvious that spinal MRI is a very useful and convenient tool to investigate the spinal circumferences, including disc, neural foramen, nerve root, and facet joint, most spine surgeons ignore the importance of looking at all aspects of their imaging and of remembering the extra-spinal causes of radiculopathy.

The abdominal aorta, commences after passing between the crura of the diaphragm on the front of the body of T12 and runs as a retroperitoneal structure along the bodies of the lumbar vertebrae until it bifurcates at the level of L4, is well visible on routine lumbar MRI including sagittal and 
axial images. An aneurysm is defined as a permanent localized dilatation of an artery having at least a 50\% increase in diameter compared with the normal ${ }^{4}$. Based on a reported maximum diameter of $20 \mathrm{~mm}$ of normal infra-renal aorta, AAA is more commonly defined as a maximum diameter of greater than $30 \mathrm{~mm}^{15)}$. Although MRI itself is not a commonly used imaging modality in the screening of AAA, it is sensitive enough to detect aneurysms on abdominal aorta ${ }^{14)}$. The rising incidence, especially high in elderly people approaching $8 \%$, and the poor prognosis in case of rupture with a mortality rate that can be as high as $90 \%$ call for early identification of AAA in all aspects of clinical practices, and spinal surgeon is not an exception ${ }^{9,11)}$.

Several reports of radiculopathy secondary to AAA have been reported previously.

Most of them described the ruptured AAA associated with retroperitoneal and iliopsoas hematoma or a false aneur$\mathrm{ysm}^{2,8)}$. Rarely has it been reported that radiculopathy associated with unruptured AAA. Smith et al. reported the unilateral radiating pain caused by unruptured aneurysmal sac encroachment upon a nerve branch of the lumbar plexus ${ }^{13)}$. Shields et al. also presented an case of a unruptured aortoiliac aneurysm with erosion into the spinal canal and neuroforamina which presented as a lumbosacral radiculopathy secondary to direct compression of nerve roots ${ }^{12)}$. In our case, the other mechanism of claudication, accelerated vascular insufficiency caused by hemodynamic change due to internal bleeding of aneurysm, can be assumed according to several reasons. First compression of psoas muscle or lumbar plexus was not definite on CT scan images. Second, significant improvement, in both symptom of claudication itself and ABI measurement, was demonstrated after only AAA repair surgery.

\section{CONCLUSION}

In this case report, we emphasize to spinal surgeons the importance of remembering to look 'just several centimeters wider' on routine MRI images when considering differential diagnoses in the outpatient clinic and to remember the extraspinal causes of radiculopathy, especially when encountering in elderly patients.

\section{REFERENCES}

1. Amato B, Markabaoui AK, Piscitelli V, Mastrobuoni G, Persico
F, Iuliano G, et al: Carotid endarterectomy under local anesthesia in elderly: is it worthwhile? Acta Biomed 76 Suppl 1: 64-68, 2005

2. Guite LA Jr., Trembly B: Ruptured abdominal aortic presenting with peripheral neuropathy. J Maine Med Assoc 65(2):34, 1974

3. Hirsch AT, Criqui MH, Treat-Jacobson D, Regensteiner JG, Creager MA, Olin JW, et al: Peripheral arterial disease detection, awareness, and treatment in primary care. JAMA 286: 1317-1324, 2001

4. Johnston KW, Rutherford RB, Tilson MD, Shah DM, Hollier L, Stanley JC: Suggested standards for reporting on arterial aneurysms. Subcommittee on Reporting Standards for Arterial Aneurysms, Ad Hoc Committee on Reporting Standards, Society for Vascular Surgery and North American Chapter, International Society for Cardiovascular Surgery. J Vasc Surg 13(3):452-458, 1991

5. Mannacio V, Di Tommaso L, De Amicis V, Musumeci F, Stassano P: Serial evaluation of flow in single or arterial Y-grafts to the left coronary artery. Ann Thorac Surg 92(5):1712-1718, 2011

6. McCulloch JA, Young PH: Essentials of Spinal Microsurgery, Philadelphia: Lippincott-Raven, 1998, pp 462-463

7. Norgren L, Hiatt WR, Dormandy JA, Nehler MR, Harris KA, Fowkes FG: Inter-Society Consensus for the Management of Peripheral Arterial Disease (TASC II). J Vasc Surg 45 Suppl S: S5-67, 2007

8. Owens ML: Psoas weakness and femoral neuropathy: neglected signs of retroperitoneal hemorrhage from ruptured aneurysm. Surgery 91(3):363-366, 1982

9. Prance SE, Wilson YG, Cosgrove CM, Walker AJ, Wilkins DC, Ashley S : Ruptured abdominal aortic aneurysm: selecting patients for surgery. Eur J Vasc Endovasc Surg 17(2):129-132, 1999

10. Rooke TW, Hirsch AT, Misra S, Sidawy AN, Beckman JA, Findeiss LK, et al: 2011 ACCF/AHA Focused Update of the Guideline for the Management of Patients With Peripheral Artery Disease (updating the 2005 guideline): a report of the American College of Cardiology Foundation/American Heart Association Task Force on Practice Guidelines. J Am Coll Cardiol 58:20202045, 2011

11. Scott RA, Vardulaki KA, Walker NM, Day NE, Duffy SW, Ashton HA, et al: The long-term benefits of a single scan for abdominal aortic aneurysm (AAA) at age 65. Eur J Vasc Endovasc Surg 21(6):535-540, 2001

12. Shields RE, Aaron JO, Postel G, Gaar E, Hourigan J: A fatal illness presenting as an S1 radiculopathy. Vascular causes of lumbar radicular pain. J Ky Med Assoc 95(7):268-270, 1997

13. Smith DL, Campbell SM: Unruptured abdominal aortic aneurysm mimicking hip joint disease. J Rheumatol 14(1):172-173, 1987

14. Sparks AR, Johnson PL, Meyer MC: Imaging of abdominal aortic aneurysms. Am Fam Physician 65(8):1565-1570, 2002

15. van der Villet JA, Boll AP: Abdominal aortic aneurysm. Lancet 349(9055):863-866, 1997 